\title{
Influence of Recycling Agent on Surface Free Energy of Asphalt Cement
}

\author{
Saad Issa Sarsam*, Rana Khalid Hamdan \\ Department of Civil Engineering, College of Engineering, University of Baghdad, Baghdad, Iraq
}

Email address:

saadisasarsam@coeng.uobaghdad.edu.iq (S. I. Sarsam)

${ }^{*}$ Corresponding author

\section{To cite this article:}

Saad Issa Sarsam, Rana Khalid Hamdan. Influence of Recycling Agent on Surface Free Energy of Asphalt Cement. American Journal of Traffic and Transportation Engineering. Vol. 4, No. 1, 2019, pp. 17-23. doi: 10.11648/j.ajtte.20190401.13

Received: March 24, 2019; Accepted: April 22, 2019; Published: May 9, 2019

\begin{abstract}
Reliable surface free energy characterization is required in order to implement the suitable recycling agent into aged asphalt. One proven method to estimate asphalt surface free energy is to calculate it using contact angles measured with various liquids. The efficiency of recycling agent in terms of its impact on rheology and surface free energy of asphalt cement is vital in the decision of recycling aged asphalt concrete. In this investigation, asphalt cement of penetration grade 40-50 was subjected to aging using the thin film oven test. The aged and the control asphalt cement samples have been digested with various percentages of two type of polymer recycling agents (Polyethylene and crumb rubber). Recycled and control asphalt cement specimens were subjected to physical and rheological properties determination, while the surface free energy was determined using Wilhelmy plate and Sessile drop methods. It was observed that the surface free energy decreases after aging, while it increases after digestion with polymers. Digestion of aged asphalt cement with polyethylene was able to retain the original surface free energy of asphalt cement before aging, while a higher percentage of 1.5 polyethylene has improved the surface free energy beyond the requirements. Digestion of aged asphalt cement with crumb rubber was able to increase the surface free energy of asphalt cement by one-fold of that before aging when Wilhelmy plate method was implemented, while a higher percentage of 1.0 of crumb rubber has improved the surface free energy beyond the requirements.
\end{abstract}

Keywords: Surface Free Energy, Crumb Rubber, Polyethylene, Rheology, Wilhelmy Plate, Sessile Drop

\section{Introduction}

Recycling of aged asphalt concrete is considered as major requirement of sustainable pavement. The selection of proper type and amount of recycling agent is vital in the decision for rehabilitation of flexible pavement. Surface free energies (SFE) of the binder can be a valuable indicator of the resistance to moisture damage along with the temperature susceptibility of asphalt binder, [1]. An investigation by Sarsam and al Azzawi, [2] stated that higher contact angle can be obtained when using sessile drop method and lower surface free energy, while when using Wilhelmy technique, lower contact angle and higher surface energy have been obtained. A study by Sarsam and al Sadik, [3] stated that thin-film oven test (TFOT) was implemented for age hardening process to simulate hot mix plant and placement conditions. The impact of aging time on physical and rheological properties of asphalt cement such as penetration, softening point, ductility, stiffness modulus, surface free energy, penetration index and bending beam rheometer BBR before and after thin film oven test with various aging periods have been modeled. Two techniques namely Wilhelmy plate (WP) and Sessile drop (SD) methods to rank moisture damage susceptibility of twelve different asphalt-aggregate combinations have been compared by Habal and Singh, [4]. Three asphalt binders: unmodified, polymer modified, and crumb rubber modified binders, and four aggregates (basalt, limestone, granite, and sandstone) were selected in their study. The contact angle of selected asphalt binders was measured using both WP and SD techniques. Thereafter, surface free energy (SFE) components of asphalt binders, bonding energy and compatibility ratio (CR) of selected asphalt-aggregate combinations were estimated. The results showed that the SD method showed a high 
variability in measurement of contact angle of asphalt binders compared to the WP method. A refined test method and analysis procedure customized to estimate asphalt surface energy using contact angles measured by the Wilhelmy plate was presented by Hefer et al, [5]. Results for five neat and three modified bitumen are interpreted to study the relationships between contact-angle based surface energies and damage in hot mix asphalt. An attempt was made by Sarsam and Lafta, [6] to prepare the modified Asphalt cement for pavement construction in the laboratory by digesting each of the two penetration-grade Asphalt cement (40-50 and 60-70) with sulfur, fly ash, fumed silica, crumb rubber and Phospho gypsum. Crumb rubber additive shows the highest creep stiffness. The softer asphalt 60-70 experience increases in the magnitude of creep stiffness at 60 seconds by $84 \%$ when compared to harder asphalt of 40-50. The sessile drop technique was performed by Wei and Zhang, [7] to obtain the contact angle between asphalt/aggregate and different probe liquids. It was found that the sessile drop technique is a convenient way to determine the static contact angle. The surface free energy of aggregate determined was found to be smaller than that measured in other techniques because of equilibrium spreading pressure. It was concluded that the work of adhesion calculated from surface free energy can be utilized to choose the best combination of asphalt and aggregate, which can work as a reference in the selection of materials. It was stated by Sarsam and Abdulhussain, [8] that the addition of $10 \%$ carbon black exhibit an increment of surface free energy of $(7.7$ and 5.8$) \%$ when tested by Wilhelmy plate and sessile drop methods respectively as compared to control asphalt. On the other hand, addition of $7 \%$ sulfur exhibit an increment of surface free energy of (2.8 and 3.1$) \%$ when tested by Wilhelmy plate and sessile drop methods respectively as compared to control asphalt. In order to use surface energy measurements to select materials for better performing asphalt pavements, it is imperative that simple, accurate, and reliable test methods be used to measure the surface energy components of asphalt binders and aggregates, and the link between surface energy and performance of mixes must be established and validated, [9].
The Wilhelmy plate device was used to determine the surface free energy of asphalt binders by Howson et al, [10] and the changes in surface free energy characteristics among different batches of binder obtained from the same producer have been evaluated. The surface free energy values for a total of 44 different types of neat and modified asphalt binders were compiled. Of these, 24 binders were obtained from seven different manufacturers and included base as well as polymer modified binders. The remaining 20 binders were obtained by modifying a subset of the 24 binders used before. The modifications included aging or addition of liquid anti-strip agents. Of these 24 binders, the surface free energy components of 21 different types of asphalt binders was determined by obtaining samples from the same source at two different points in time. A study by Sarsam and Abdulhussain, [11] assessed how surface free energy characteristics and the blending techniques alter the properties of modified asphalt cement. The impact of two blending techniques of asphalt and additives; the traditional oven heating and stirring and blending inside the cooking pressure vessel have been assessed. The surface free energy component of the prepared asphalt cement mixtures was measured using the Wilhelmy plate and sessile drop methods. For comparison, the surface free energy characteristics of the unmodified bitumen were also determined. It was concluded that pressure vessel blending is more appropriate for enhancing the required homogeneity in the blending process, it exhibits higher surface free energy of (7.4 and 13.2)\% for carbon black and sulfur additives respectively with sessile drop method. Wilhelmy plate method shows that the surface free energy is lower by $6.3 \%$ and higher by $10 \%$ for carbon black and sulfur respectively when the pressure vessel technique was implemented as compared to oven heating technique.

\section{Materials and Methods}

\subsection{Asphalt Cement}

Asphalt cement of 40-50 penetration grade was obtained from Dora refinery; the physical properties are listed in Table 1.

Table 1. Physical Properties of Asphalt Cement.

\begin{tabular}{|c|c|c|c|}
\hline Test Procedure ASTM [13] & Result & Unit & $\begin{array}{c}\text { SCRB } \\
\text { Specification [14] }\end{array}$ \\
\hline Penetration $\left(25^{\circ} \mathrm{C}, 100 \mathrm{~g}, 5 \mathrm{sec}\right)$ ASTM D 5 & 43 & $1 / 10 \mathrm{~mm}$ & $40-50$ \\
\hline Ductility $\left(25^{\circ} \mathrm{C}, 5 \mathrm{~cm} / \mathrm{min}\right)$. ASTM D 113 & 167 & $\mathrm{Cm}$ & $\geq 100$ \\
\hline Softening point (ring \& ball). ASTM D 36 & 54 & ${ }^{\circ} \mathrm{C}$ & -- \\
\hline After Thin-Film Oven Test ASTM D-1754 & & & \\
\hline Retained penetration of original,\% ASTM D 946 & 87 & $\%$ & $<55$ \\
\hline Ductility at $25^{\circ} \mathrm{C}, 5 \mathrm{~cm} / \mathrm{min},(\mathrm{cm})$ ASTM D-113 & 147 & $\mathrm{Cm}$ & $>25$ \\
\hline Loss in weight $\left(163^{\circ} \mathrm{C}, 50 \mathrm{~g}, 5 \mathrm{~h}\right) \%$ ASTM D-1754 & 0.32 & $\%$ & - \\
\hline
\end{tabular}

\subsection{Crumb Rubber}

It was produced by mechanical shredding and was obtained from tires factory at AL-Najaf governorate, the rubber type is (recycled) from used tires. Table 2 show the grain sizes distribution of crumb rubber.
Table 2. Gradation of crumb rubber.

\begin{tabular}{lll}
\hline Sieve No. & Sieve Size(mm) & Passing by weight\% \\
\hline No.16 & 1.18 & 100 \\
No.30 & 0.9 & 78 \\
No.50 & 0.3 & 25 \\
No.200 & 0.075 & 0 \\
\hline
\end{tabular}




\subsection{Polyethylene}

It was a Low-Density Polymers, found to be suitable for blending with asphalt with a melting temperature not more than $180^{\circ} \mathrm{C}$. Table 3 show the mechanical and thermal Properties of Polyethylene.

Table 3. Mechanical and thermal properties of low-density Polyethylene.

\begin{tabular}{lll}
\hline Properties & Unit & Value \\
\hline Tensile strength & $\mathrm{MPa}$ & 10 \\
Tensile Elongation & $\%$ & $>350$ \\
Flexural Modulus & $\mathrm{MPa}$ & 8 \\
Hardness (Shore D) & & 50 \\
Vicat Softening point & ${ }^{\circ} \mathrm{C}$ & 88 \\
Brittleness Temperature & ${ }^{\circ} \mathrm{C}$ & $\leq 175$ \\
\hline
\end{tabular}

\subsection{Aging of Asphalt Cement}

To simulate the aging process of asphalt cement during its service life in the field, Asphalt cement was subjected to aging process using the thin film oven test apparatus, asphalt cement practices $163^{\circ} \mathrm{C}$ of heating for five hours in the rotating shelf of the oven. Asphalt cement was collected after the heating and cooled to room temperature. It was denoted as aged asphalt cement.

\subsection{Preparation of Recycled Asphalt Cement (Asphalt Cement Blended with Low-Density Polyethylene)}

The aged asphalt cement was recycled by digestion with polyethylene, asphalt cement was heated to $150^{\circ} \mathrm{C}$ and then blended with Low-Density Polyethylene with different content $(0.5,1$ and $1.5 \%$ by weight of asphalt cement) using mechanical mixer, it was prepared in the laboratory at a blending speed of about $200 \mathrm{rpm}$ and elevated temperatures $\left(160^{\circ} \mathrm{C}\right)$ for 60 minutes to promote the physical and chemical bonding of the components.

\subsection{Preparation of Recycled Asphalt Cement (Asphalt Cement Blended with Crumb Rubber)}

The aged asphalt cement was recycled by digestion with crumb rubber using the wet process. The asphalt cement was heated to $150^{\circ} \mathrm{C}$ and then blended with crumb rubber with different content $(0.5,1$ and $1.5 \%$ by weight of asphalt cement) at a blending speed of about $1500 \mathrm{rpm}$ for 60 minutes in the laboratory using mechanical mixer to promote the physical and chemical bonding of the components. During the blending process, the crumb rubber dispersed and reacts with the asphalt. Swelling and formation of bubbles could be observed after the blending process.

\subsection{Determination of Surface Free Energy of Recycled Asphalt Cement by Sessile Drop Method (SDM)}

The surface free energy is required to compute work of adhesion between aggregate and asphalt binder. These quantities are related to moisture sensitivity and adhesive fracture properties of the asphalt binder. The three components of which the surface free energy is composed for asphalt binder are the Lifshitz-van der Waals component, the Lewis base component and the Lewis acid component, [12]. The test sample was prepared by cleaning the surface of the glass slide which was used as a substrate for the asphalt binder, then the asphalt binder was heated to mixing temperature, a small quantity of asphalt binder was poured on the substrate. The quantity of asphalt poured forms an area of approximately $(5 \times 5) \mathrm{cm}$ in size, then left to cool for $24 \mathrm{~h}$ at room temperature. By using micro syringe, a probe liquid was dispensed over the prementioned smooth horizontal surface coated with asphalt from the top of the sample position, the tip of the micro syringe needle was approximately $5 \mathrm{~mm}$ away, Figure 1 shows a schematic diagram of the sessile drop device. By using a digital camera, the image of the drop of the liquid formed over the surface of the binder was captured and by analyzing the image using (Comef 4.4) software, contact angles were obtained. With the aid of work of adhesion theory and mathematical models, the three surface energy components of the asphalt binder were determined.

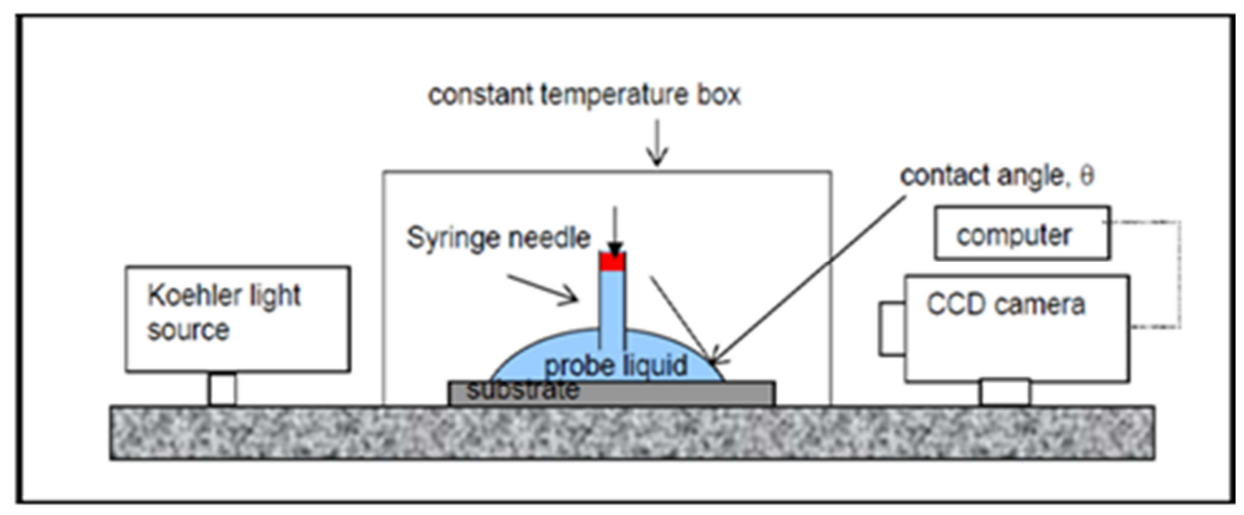

Figure 1. Schematic diagram of the sessile drop device.

Figure 2 shows the image of the drop when using different probe liquids. Figure 3 shows the desktop of the COMEF 4.4 software. Three probe liquids were used to measure the contact angle (distilled water, glycerol, Formamid). The surface free energy component of a solid surface was determined by measuring its contact angles with various probe liquids for at least three replicates with each probe liquid. The surface free energy was calculated using the mathematical models presented by Little and Bhasin, [9]. 


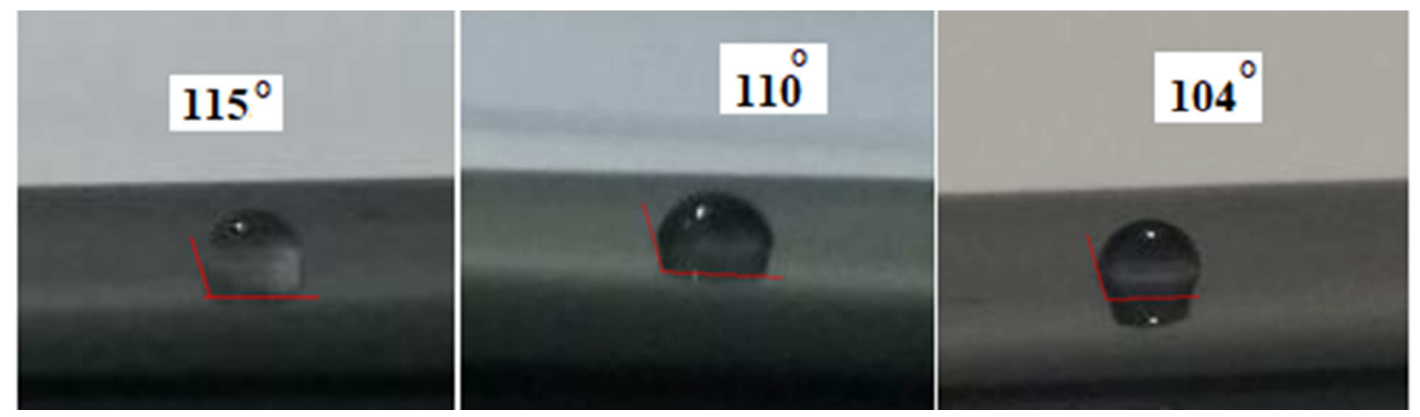

Figure 2. Image of the contact angle of the drop when using different probe liquids.

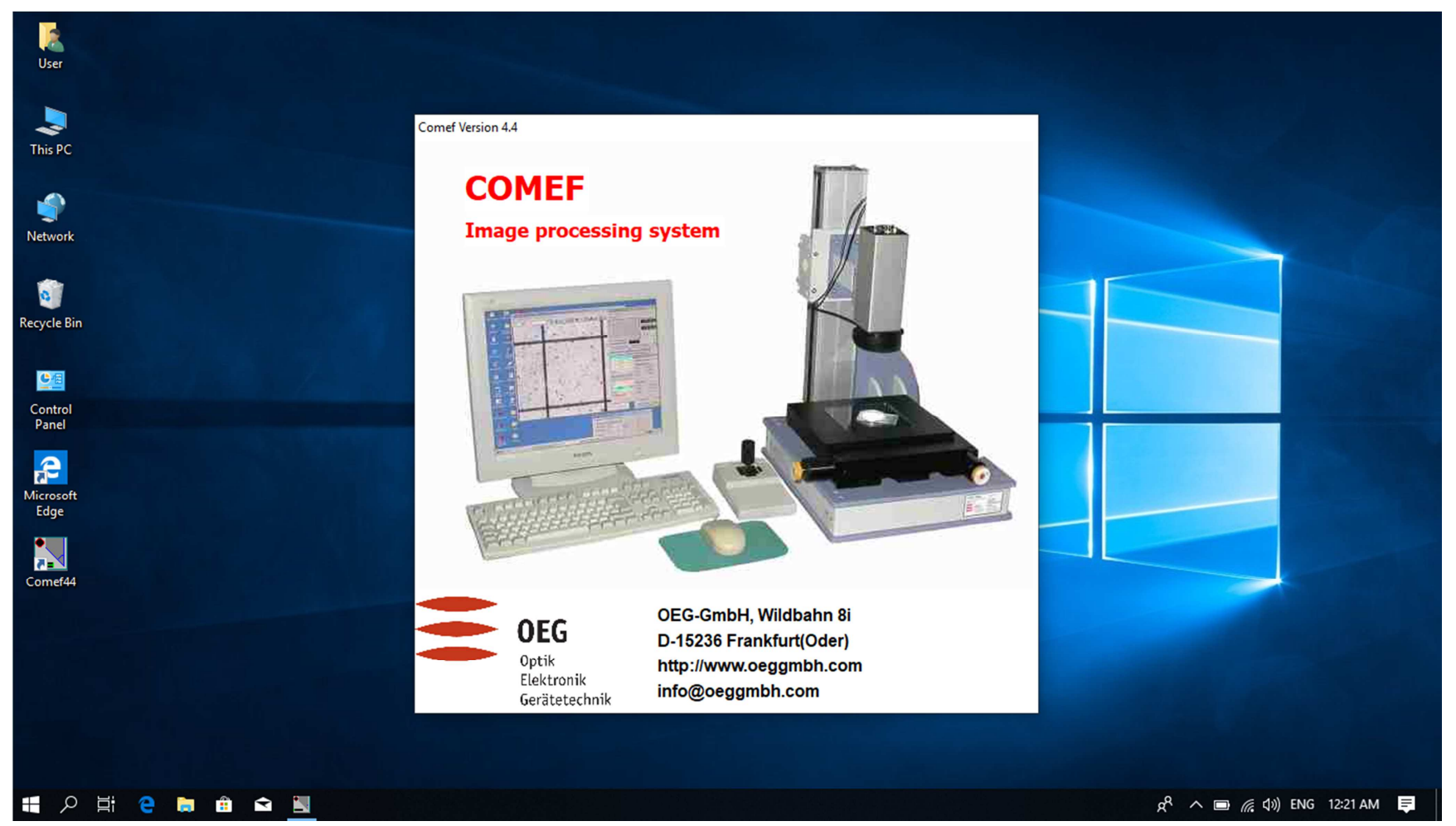

Figure 3. Desktop of the COMEF 4.4 software.

\subsection{Determination of Surface Free Energy of Recycled Asphalt Cement by Wilhelmy Plate Method (WPM)}

The Wilhelmy plate device was implemented to determine the three surface energy components of asphalt binders. This test method covers the procedures for preparing samples and measuring contact angles. The asphalt binder was heated in an oven to the mixing temperature. The glass slides were cleaned, dried and the blue flame was used to remove any moisture from coated slides by passing the end of the glass through the burner six times on each side as shown in Figure 4 to a depth of approximately $15 \mathrm{~mm}$, the slide was dipped into the molten asphalt binder and the excess binder could drain from the slide. Then the slides were placed in the slotted slide holder and left for $24 \mathrm{~h}$ to cool, the width and thickness of the asphalt binder slide was measured to obtain the perimeter. Figure 5 exhibit part of the prepared glass slides.

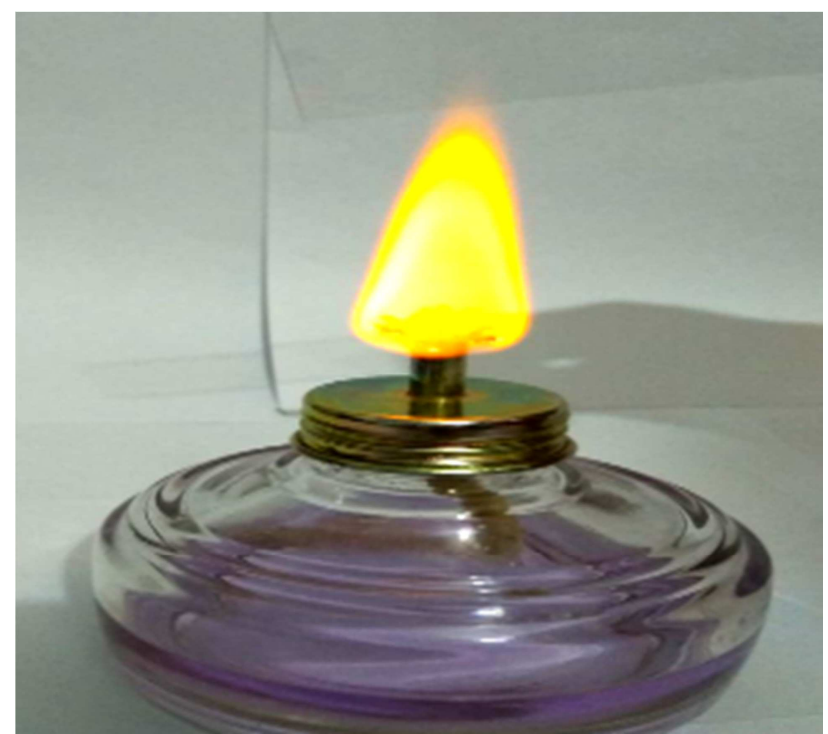

Figure 4. Blue flame implemented. 


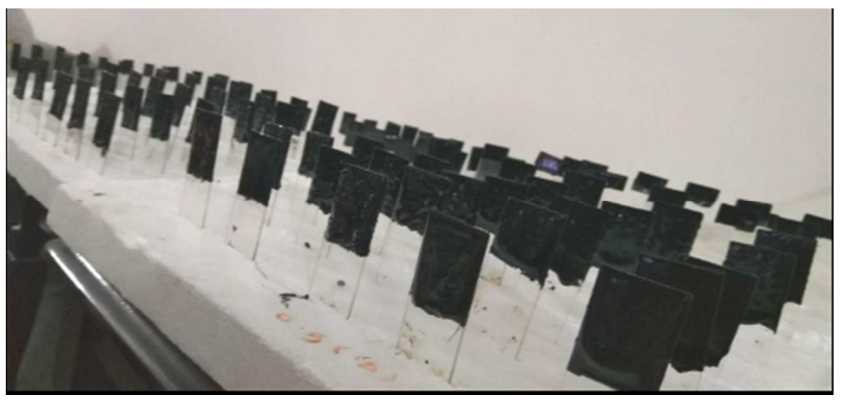

Figure 5. Part of the prepared glass slides.

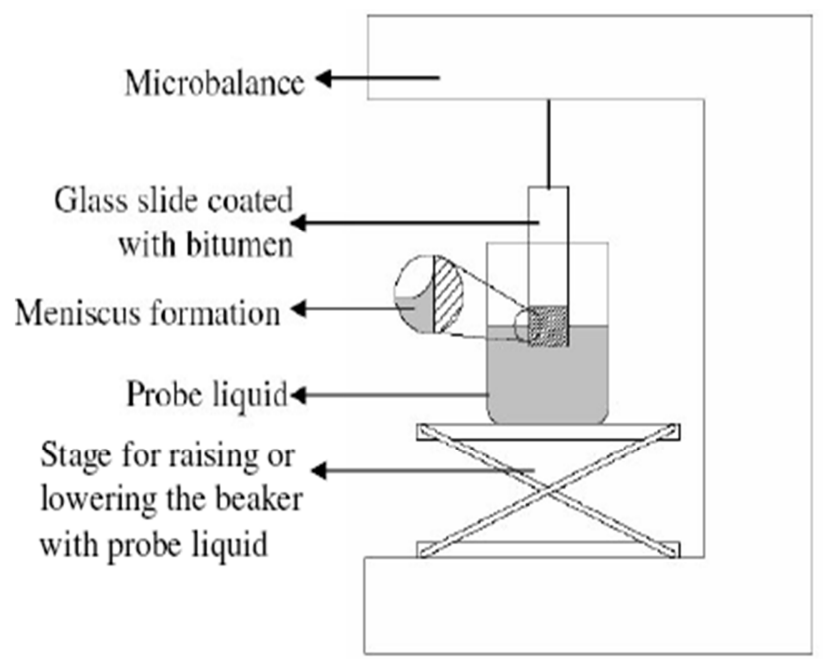

Figure 6. Schematic diagram of Wilhelmy plate Technique.

Three group of glass slide with dimensions $(25.4 \mathrm{mmx}$ $76.2 \mathrm{mmx} 1 \mathrm{~mm}$ ) were prepared, each group consist of 9 slides coated with control asphalt binder (without aging), aged asphalt binder and modified asphalt. Then the slides were immersed in the different probe liquids in the beaker at steady speed and while the slide was in its last position in the liquid, the slide was captured by the digital camera. Digital balance was used with sensitivity of $0.2 \mathrm{gm}$ and a capacity of $(500 \mathrm{~g})$ to measure the forces. Three probe liquids were used (Water, Glycerol and Formamid) and the beaker was placed on the balance. The glass slide was linked and downloaded at steady and slow speed inside the glass beaker, when the slide was in touched with the liquid, the balance reading was recorded. Figure 6 shows the Schematic diagram of Wilhelmy plate Technique. By using the image processing software (Comef 4.4), a dynamic contact angle was measured.

The contact angle of the probe liquid with the surface of the asphalt binder can be determined from simple force equilibrium conditions which is the difference between weight of a plate measured in air and partially submerged in a probe liquid was expressed in terms of liquid surface energy, buoyancy of the liquid, geometry of the plate and contact angle. The surface energy was calculated using the mathematical models presented by Little and Bhasin, [9] and Habal and Singh, [4].

\section{Results and Discussion}

Table 4 exhibit the influence of aging process and implementation of recycling agents on rheological properties of asphalt cement. It can be observed that aging of asphalt cement causes reduction in penetration index PI by $74.6 \%$ and increment of the penetration viscosity number PVN and stiffness modulus by (10 and 26.6$) \%$ respectively as compared with the control specimen. This could be attributed to the stiffening of asphalt cement due to loss of volatiles which indicate lower temperature susceptibility. When the aged asphalt was digested with $(0.5,1.0$ and 1.5$) \%$ of polyethylene recycling agent, the PI values increases by $(189$, 484 , and 600$) \%$ respectively, while the temperature of equivalent stiffness TES increases by $22 \%$ regardless of the recycling agent quantity. The viscosity temperature susceptibility VTS decreases by $(13,20$ and 14)\% after the addition of $(0.5,1.0$ and 1.5$) \%$ of polyethylene respectively.

Table 4. Influence of recycling agents on rheological properties of asphalt cement.

\begin{tabular}{|c|c|c|c|c|c|c|c|c|}
\hline \multirow{2}{*}{ Rheological property } & \multirow{2}{*}{$\begin{array}{l}\text { Control } \\
\text { asphalt }\end{array}$} & \multirow{2}{*}{$\begin{array}{l}\text { Aged } \\
\text { asphalt }\end{array}$} & \multicolumn{3}{|c|}{ Polyethylene recycling agent } & \multicolumn{3}{|c|}{ Crumb rubber recycling agent } \\
\hline & & & $0.5 \%$ & $1 \%$ & $1.5 \%$ & $0.5 \%$ & $1 \%$ & $1.5 \%$ \\
\hline PI & -0.75 & -0.19 & -0.55 & -1.11 & -1.33 & -0.642 & -0.783 & -0.812 \\
\hline PVN & -1.0178 & -1.12 & -0.89 & -0.96 & -1.15 & -0.621 & -0.246 & -0.592 \\
\hline VTS & 3.84 & 3.85 & 3.37 & 3.09 & 3.32 & 2.472 & 2.459 & 3.310 \\
\hline TES & -31 & -32 & -39 & -39 & -40 & -33 & -32 & -31 \\
\hline Stiffness modulus N/m2 & $4.5 \times 108$ & $5.7 \times 108$ & $2.0 \times 109$ & $2.5 \times 109$ & $2.3 \times 109$ & $2.0 \times 109$ & $2.4 \times 109$ & $2.2 \times 109$ \\
\hline
\end{tabular}

When the aged asphalt cement was digested with $(0.5,1.0$ and 1.5$) \%$ of crumb rubber recycling agent, the PI values increases by $(237,310$, and 326$) \%$ respectively, while the variation of temperature of equivalent stiffness TES was not significant regardless of the recycling agent quantity. The viscosity temperature susceptibility VTS decreases by $(36,36$ and 14$) \%$ after the addition of $(0.5,1.0$ and 1.5$) \%$ of crumb rubber respectively. Fig. 7 exhibit the impact of aging on the surface free energy of asphalt cement, it can be noted that the surface free energy decreases by (5.3 and 76)\% when implementing Wilhelmy plate and Sessile drop testing techniques respectively, however, the reduction in surface free energy due to aging was significant with Sessile drop method. Such behaviour may be attributed to the loss of volatiles during aging process, increased stiffness, and reduction of support to the flexibility of asphalt cement. 

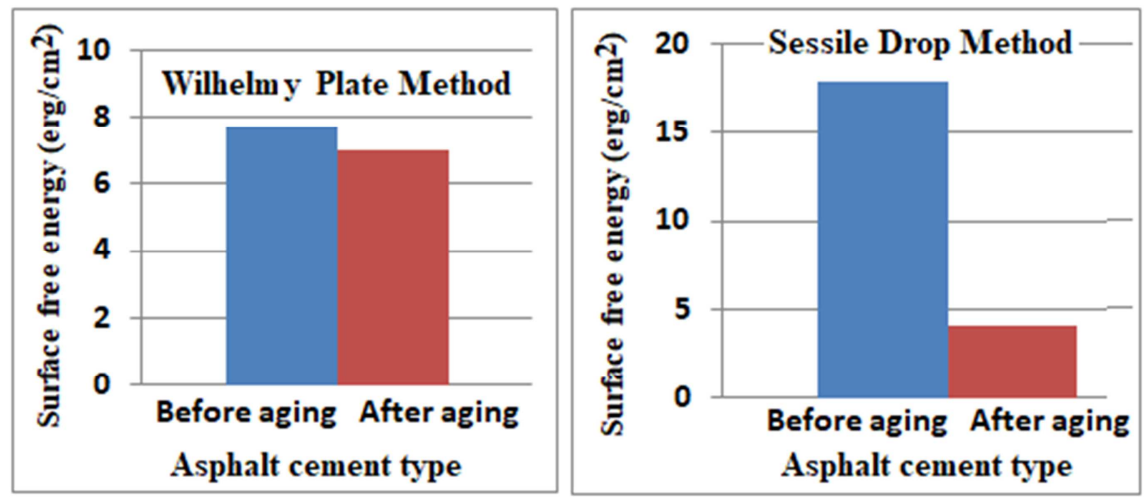

Figure 7. Impact of aging on surface free energy of asphalt binder.

Figure 8 present the influence of polyethylene on surface free energy, it can be noted that within the limitations of the testing program, the surface free energy increases with the increment of polyethylene regardless of the testing technique implemented. It was observed that measurement of surface free energy by Sessile drop method exhibit higher values by $50 \%$ than that obtained when using Wilhelmy plate testing method. Such finding agrees well with work reported by Sarsam and Abdulhussain, [11] and Sarsam and Al-Azzawi,
[2]. Digestion of aged asphalt cement with polyethylene was able to retain the original surface free energy of asphalt cement before aging, while a higher percentage of 1.5 polyethylene has improved the surface free energy beyond the requirements. This may be attributed to the added flexibility to asphalt cement by digestion with polyethylene. This was further supported by the increased resistance to temperature susceptibility of the recycled asphalt cement.

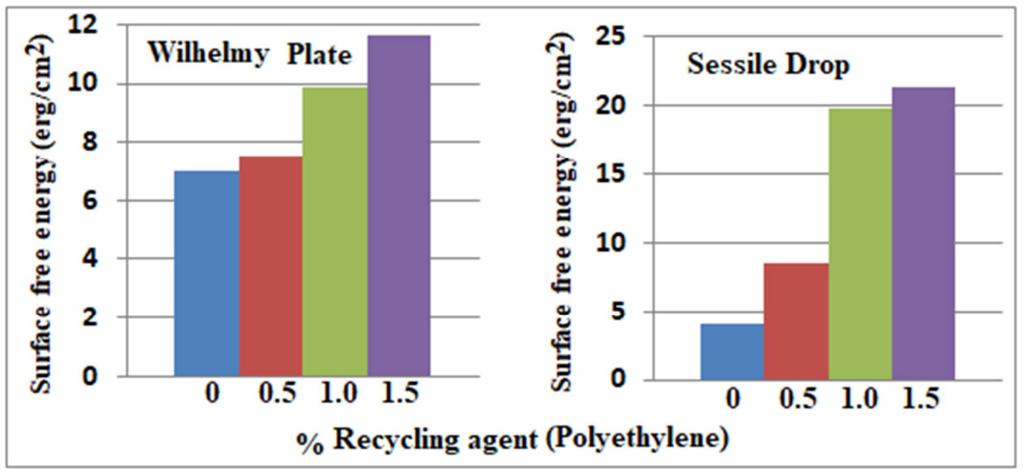

Figure 8. Influence of polyethylene addition on surface free energy.

Figure 9 exhibit the influence of crumb rubber on surface free energy, it can be noted that the surface free energy increases as the crumb rubber percentage increase up to an optimum rubber content of $(0.5-1.0) \%$, then decreases with further increase in rubber content regardless of the testing technique adopted. It can be observed that digestion of aged asphalt cement with crumb rubber was able to increase the surface free energy of asphalt cement by one-fold of that before aging when Wilhelmy plate method was implemented, while a higher percentage of 1.0 of crumb rubber has improved the surface free energy beyond the requirements. On the other hand, the improvement in surface free energy was marginal when Sessile drop method was adopted.

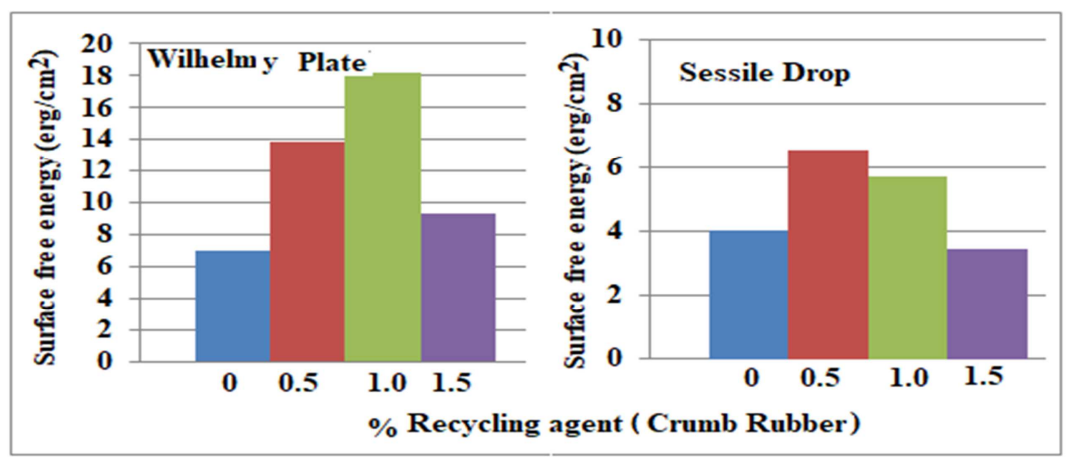

Figure 9. Influence of crumb rubber addition on surface free energy. 


\section{Conclusions}

Based on the limitation of the testing adopted, the following conclusions can be drawn.

(1) Aging of asphalt cement causes reduction in penetration index PI by $74.6 \%$ and increment of the penetration viscosity number PVN and stiffness modulus by (10 and 26.6$) \%$ respectively as compared with the control specimen.

(2) When the aged asphalt cement was digested with $(0.5$, 1.0 and 1.5$) \%$ of polyethylene recycling agent, the PI values increases by $(189,484$, and 600$) \%$ respectively, while the temperature of equivalent stiffness TES increases by $22 \%$ regardless of the recycling agent quantity. The viscosity temperature susceptibility VTS decreases by $(13,20$ and 14$) \%$ after the addition of $(0.5$, 1.0 and 1.5$) \%$ of polyethylene respectively.

(3) When the aged asphalt cement was digested with $(0.5$, 1.0 and 1.5$) \%$ of crumb rubber recycling agent, the PI values increases by $(237,310$, and 326$) \%$ respectively. The viscosity temperature susceptibility VTS decreases by $(36,36$ and 14$) \%$ after the addition of $(0.5,1.0$ and $1.5) \%$ of crumb rubber respectively.

(4) The surface free energy of asphalt cement decreases by (5.3 and 76)\% when implementing Wilhelmy plate and Sessile drop testing techniques respectively after aging.

(5) Digestion of aged asphalt cement with polyethylene was able to retain the original surface free energy of asphalt cement before aging, while a higher percentage of 1.5 polyethylene has improved the surface free energy beyond the requirements.

(6) Digestion of aged asphalt cement with crumb rubber was able to increase the surface free energy of asphalt cement by one-fold of that before aging when Wilhelmy plate method was implemented, while the improvement in surface free energy was marginal when Sessile drop method was adopted.

\section{References}

[1] N. M. Wasiuddin, H. J. Barraza, M. M. Zaman, and E. A. O' Rear, "Assessment of Surface Free Energy Characteristics of Performance Graded Asphalt Binders" Advances in Pavement Engineering. 2005. http: //Doi:10.1061/40776 (155) 12.

[2] S. I. Sarsam and E. Al-Azzawi "Assessment of Asphalt Binder Stripping using Surface Free Energy" Research and Application of Material journal, RAM, Vol. 1 No. 3, 2013 (P 27-30), Sciknow Publications Ltd. USA. 2013.

[3] S. I. Sarsam and S. Al-Sadik "Modeling Aging Impact on
Physical Properties of Asphalt Cement" Research Journal of Modeling and Simulation, RJMS, May, Vol. 1 (2) (P20-29). Sciknow Publications Ltd. USA. 2014.

[4] A. Habal, and D. Singh, 'Comparison of Wilhelmy plate and Sessile drop methods to rank moisture damage susceptibility of asphalt - Aggregates combinations" Construction and Building $\begin{array}{lll}\text { Materials, } & 113, & 351-358 .\end{array}$ http://Doi:10.1016/j.conbuildmat. 2016.03.060.

[5] A. W. Hefer, A. Bhasin, and D. N. Little, "Bitumen Surface Energy Characterization Using a Contact Angle Approach" Journal of Materials in Civil Engineering, 18 (6), 759-767. 2006. http: //Doi:10.1061/(ASCE)0899-1561 (2006).

[6] S. I. Sarsam and I. M. Lafta "Assessing Rheological Behavior of Modified Paving Asphalt Cement" American Journal of Civil and Structural Engineering, (AJCSE), Vol. 1 (3) p. 47-54, July. Sciknow Publications Ltd. USA. 2014.

[7] J. Wei and Y. Zhang, "Application of Sessile Drop Method to Determine Surface Free Energy of Asphalt and Aggregate" Journal of Testing and Evaluation, Vol. 40, No. 5, pp. 807-813, 2012. https: //Doi.org/10.1520/JTE20120060. ISSN 0090-3973.

[8] S. I. Sarsam and M. K. Abdulhussain "Assessing Surface Free Energy Component of Modified Asphalt Cement" Proceedings, 4th Conference of the Middle East Society of Asphalt Technologists, MESAT 2018, July 4-6, Beirut- Lebanon pp. 65-75. 2018.

[9] D. Little and A. Bhasin "Using Surface Energy Measurements to Select Materials for Asphalt Pavement" NCHRP Web only document 104, Final Report for NCHRP Project 9-37. National Cooperative Highway Research Program. USA. 2006.

[10] J. Howson, A. Bhasin, E. Masad, R. Lytton, and D. Little "Development of a database for surface energy of aggregates and asphalt binders" Report FHWA/TX-09/5-4524-01-1, Texas Department of Transportation, Research and Technology Implementation Office, USA. 2009.

[11] S. I. Sarsam and M. K. Abdulhussain "Influence of Blending Technique on Surface Free Energy of Modified Asphalt Cement" Trends in Transport Engineering and Applications, STM Journals, Vol.5 Issue 1, Pp. 22-31. 2018.

[12] G. H. Hamedi, and F. Nejad, "Using energy parameters based on the surface free energy concept to evaluate the moisture susceptibility of hot mix asphalt" Road Materials and Pavement Design, 16 (2), 2014. 239-255. http: //Doi:10.1080/14680629.2014.990049.

[13] ASTM, "Road and Paving Materials" Annual Book of ASTM Standards, Volume 04.03, American Society for Testing and Materials, USA. 2013.

[14] SCRB "Standard Specification for Roads and Bridges" Section R/9, Revised Edition. State Commotion of Roads and Bridges, Ministry of Housing and Construction, Republic of Iraq. 2003. 